\title{
Um romance hiper-circuitado: 2019 não passa e o curto da tradição literária
}

\section{A hyper-circuited novel: 2019 não passa and a short circuit in literary tradition}

\section{Una novela hiper-circuitada: 2019 não passa y el cortocircuito de la tradición literaria}

\author{
iD (9) Júlia de Mello Silva Oliveira \\ Universidade Federal de São Carlos (UFSCar), São Carlos, São Paulo, Brasil. \\ E-mail: mellodeju@gmail.com \\ (iD) Nair Renata Amâncio \\ Universidade Federal de São Carlos (UFSCar), São Carlos, São Paulo, Brasil. \\ E-mail: nairrenataamancio@gmail.com \\ (iD) Rejane Cristina Rocha \\ Universidade Federal de São Carlos (UFSCar), São Carlos, São Paulo, Brasil. \\ E-mail: rjncris@gmail.com
}

\begin{abstract}
Resumo: Se a arte - e, por extensão, a literatura - sempre se fez com os meios do seu tempo, como propôs Arlindo Machado, na contemporaneidade digital os meios digitais oferecem possibilidades e impõem restrições aos escritores, a depender de como eles optam por manipular códigos informáticos ou, ainda, experimentar com as mídias a fim de expandir e/ou recusar as especificidades dos gêneros literários nascidos e consolidados ao longo da cultura impressa. Este artigo analisa o romance de Instagram, 2019 não passa, a fim de discutir de que maneira a sua inscrição material em uma rede social altera/amplia o que temos identificado como próprio do gênero romance.
\end{abstract}

Palavras-chave: Literatura digital. Romance. Instagram. 2019 não passa. 
Abstract: If art - and by extension literature - has always been done with the media of its time as proposed by Arlindo Machado, in digital contemporaneity the digital media offer possibilities and impose restrictions on writers depending on how they choose to manipulate computer codes or, yet, experiment with the media in order to expand and/or refuse the specificities of literary genre born and consolidated throughout printed culture. Thus, this article analyzes the Instagram novel intitulated 2019 não passa in order to discuss how its material subscription, in a social network, alters / expands what we have identified as typical of the novel genre.

Keywords: Digital Literature. Novel. Instagram. 2019 não passa.

Resumen: Se el arte - y, por extensión, la literatura - siempre se ha hecho con los medios de su tiempo, como propuso Arlindo Machado, en la contemporaneidad digital los medios ofrecen posibilidades y imponen restricciones a los escritores, a depender de cómo ellos deciden manipular códigos informáticos o, aún, experimentar con las mídias con el fin de expandir y/o rechazar las especificidades de los géneros literarios nacidos y consolidados a lo largo de la cultura impresa. Este artículo analiza la novela de Instagram 2019 não passa con el fin de discutir de qué modo su inscripción material, en una red social, cambia/ expande lo que tenemos identificado como propio del género novela.

PalabrasClave: Literatura digital. Novela. Instagram. 2019 não passa.

Submetido em 30 de maio de 2021

Aceito em 11 de agosto de 2021.

Publicado em 08 de dezembro de 2021. 


\section{A literatura digital cooptando a rede}

É cada vez mais incontornável a necessidade de se pensar a literatura na sua relação com a digitalidade. A teórica Katherine Hayles (2009), para além das produções literárias digitais nas suas especificidades, também aponta que toda a literatura produzida no século XXI é computacional (HAYLES, 2009). Assim, nos últimos anos, tem-se criado uma divisão operacional entre a literatura digital e a literatura produzida para e/ou no contexto digital, que marca um campo de discussão a respeito do que tem se constituído como literatura digital. Os teóricos que têm se dedicado a compreender as produções literárias, na sua relação direta com a digitalidade, pontuam que estabelecer uma diferenciação entre literatura digital e literatura produzida no contexto digital é condição substancial para a demarcação do campo de estudo.

Ainda que toda a literatura seja computacional, como colocou Katherine Hayles (2009), algumas estratégias de delimitação são proveitosas para um campo ainda emergente. Assim, é corrente, nas definições que circunscrevem o campo de estudo literário digital, desdobramentos como os que propõe Carolina Gainza (2021, p. 335):

la denominación "digital" permite delimitar una literatura propia de esta época, que refiere a prácticas relacionadas con la experimentación con el lenguaje de códigos o con medios digitales, como las redes sociales. Por otra parte, y este quizás es un elemento que ha marcado las literaturas digitales en la región, su desarrollo ha estado asociado a prácticas vinculadas a la cultura libre, es decir, aprovechar la libertad que permite internet y las nuevas tecnologías no solo para circular libremente las obras, sino que también para potenciar prácticas vinculadas a la copia, la piratería y el hacking como herramientas artísticas [...] podemos identificar dos grandes ramificaciones de la literatura digital: aquella que experimenta directamente con el código, donde podemos observar hipertextos, poesía de código, bots 
literarios o literaturas generadas por algoritmos, y aquella que experimenta con medios digitales, donde encontramos la literatura en twitter, Instagram, Facebook, la meme-literatura, poesía de emojis, entre otras manifestaciones. En ambas el elemento subyacente es el código, con diferentes niveles de consciencia respecto a este como lenguaje.

As definições de um campo sempre se constituem por meio de uma análise criteriosa dos produtos da literatura (EVEN-ZOHAR, 2017) e, no caso específico da literatura digital, não há ainda um sistema literário plenamente circunscrito, o que provoca não uma dissonância, mas uma diversidade de produções e experimentações que um sistema em formação encontra entraves para delimitar. É com base na percepção desse cenário que apontamos que o atual contexto brasileiro coloca questões importantes para as emergentes definições de literatura digital. Tais questões se referem ao fato de que, sendo o Brasil um país pertencente à periferia do desenvolvimento tecnológico, nem sempre as produções literárias digitais produzidas por autores brasileiros se ajustam ao que o campo tem estabelecido como canônico. Por isso é que importa a definição de Gainza, que abarca uma produção literária digital que, low tech, experimenta com os meios digitais mais do que com os códigos, fazendo uso de plataformas pré-programadas, "hackeadas" (GAINZA, 2016) e "desprogramadas" (MACHADO, 2007) em suas funções originais para assumir efeitos artísticos.

Isso posto, interessa-nos, neste artigo, discutir o objeto digital (MANOVICH, 2005) 2019 não passa (@2019naopassa), construído no Instagram, como pertencente a esse contexto de desbordamento das definições de literatura digital, dos gêneros e formas literários construídos pela tradição ocidental da cultura impressa (DARNTON, 1990). Com isso, pretendemos compreender melhor o funcionamento de uma expressão literária emergente, no interior das especificidades da cultura digital no Brasil, e como ela põe em questão a tradição teórico-crítica estabelecida ao longo do tempo acerca da literatura e do gênero romance. 
Florência Garramuño (2014), em seu livro intitulado Frutos Estranhos: sobre a inespecificidade na estética contemporânea, discute uma série de produções artístico-literárias que não se enquadrariam nos paradigmas que, em algum momento, foram estabelecidos como próprios da literatura. Essa discussão nos ajuda a refletir sobre como a obra, que analisamos neste artigo, coloca em questão tanto a especificidade do paradigma literário subordinado à cultura impressa, quanto a especificidade de uma definição de literatura digital que, num primeiro momento, começou a se consolidar à revelia das características da cultura digital produzida em países da periferia do desenvolvimento tecnológico.

Conceitos que foram considerados pela autora como práticas da impertinência, por abordarem uma série de manifestações artísticas que não condizem com os centros e com as delimitações, são oportunos para a reflexão que propomos acerca desse objeto digital:

A articulação dos textos com e-mails, blogs, fotografias, discursos antropológicos, entre muitas outras variantes [...] cifra nessa heterogeneidade uma vontade de imbricar as práticas literárias na convivência com a experiência contemporânea. Para essa literatura, uma literatura estritamente "disciplinada" ou disciplinar pouco parece poder captar. Nesse campo expansivo também está a ideia de uma literatura que se figura como parte do mundo e imiscuída nele, e não como esfera independente e autônoma. É sobretudo esta questão, embora difícil de conceitualizar, o sinal mais evidente de um campo expansivo, porque demonstra funções extrínsecas ao próprio campo disciplinar (GARRAMUÑO, 2014, p. 37).

Pensando no conceito de campo expandido, na construção de uma literatura que se configura no contexto em que as práticas artísticas se dão em consonância com as práticas culturais e cotidianas contemporâneas, percebemos que há, em muitos textos literários, traços de digitalidade ou "articulação", como prefere Gar- 
Um romance hiper-circuitado: 2019 não passa e o curto da tradição literária Júlia de Mello Silva Oliveira • Nair Renata Amâncio • Rejane Cristina Rocha

ramuño (2014). É nesse sentido que afirmamos que "a teoria das mídias mostra como as novas tecnologias modificam nossas experiências do mundo, porque elas mudam, na realidade, as próprias condições da experiência estética" (KLUCINKAS \& MOSER, 2007, p. 28). Sendo assim, a literatura digital é parte de um cenário em expansão, caracteriza-se como uma literatura oriunda de uma estética própria do meio digital.

\section{O literário e o instagram}

Considerando a efemeridade e a transitoriedade das redes (BEIGUELMAN, 2014), cabe-nos apresentar e descrever a rede social Instagram, com o objetivo de estabelecer critérios que subsidiem a leitura de @2019nãopassa como um objeto digital que subverte e potencializa o uso dessa rede social.

O Instagram figura como uma das maiores redes sociais ${ }^{1}$ do mundo e segue constantemente inovando suas funcionalidades. Segundo relatório realizado pela companhia Data Reportal2, em janeiro de 2021, o Instagram é a segunda rede social com mais usuários ativos no mundo e no Brasil. Desde sua criação até hoje, foram vários os novos recursos implementados: do IOS para o Android e do mobile ao desktop, dos perfis abertos aos fechados e dos pessoais aos empresariais, dos filtros para imagens no feed aos filtros, máscaras e stickers e outras features para stories (que exploram, inclusive, os limites da realidade aumentada), dos comentários, curtidas e salvamentos às direct messages, das lives e do IGTV ao Reels, do feed de notícias do usuário ao recurso de explorar e de navegar entre hashtags e localizações, das imagens editadas e compartilhadas às imagens com a funcionalidade Shopping, do temporário ao destaque, dos seguidores aos melhores amigos, do orgânico ao pago, da sociabilidade ao monitoramento das métricas.

\footnotetext{
1 Para uma discussão introdutória, mas esclarecedora, sobre o conceito de "rede social" nas plataformas on-line, consulte Recuero (2009).

2 Para saber sobre a companhia, suas fontes de dados e metodologias de pesquisa, acesse: https://datareportal.com/data-sources e https://datareportal.com/about. Para acessar a pesquisa global a que fazemos referência: https://datareportal.com/ reports/digital-2021-global-overview-report (slides 78 a 103 e 128 a 139) e para acessar a pesquisa específica sobre o Brasil: https://datareportal.com/reports/digital-2021-brazil (slides 11, 43 a 59 e 66).
} 
Inspirado nas câmeras fotográficas Kodak Instamatic e Polaroid e no design do iPhone, o Instagram foi criado em 2010, por um brasileiro e por um norte-americano, surgindo como a rede social de edição e compartilhamento de fotos (MANOVICH, 2016b; 2016c). Dado seu sucesso, já nos primeiros anos de seu lançamento, em 2012, foi comprado pelo Facebook, que Ihe acrescentou funcionalidades e habilitou sua interface para empresas. O fato é que o aplicativo popularizou a edição e compartilhamento de fotos entre pessoas comuns (não foi pensado para fotógrafos profissionais) que publicam fotos de seu cotidiano. Grande parte dos usuários do Instagram o utilizam em "home mode" (MANOVI$\mathrm{CH}, 2016 a$; 2016b), i.e., as imagens publicadas, em regra, dizem respeito a assuntos tradicionais: comidas, comemorações, família, amigos, autorretratos ou selfies etc. Os autores das fotos compartilham aquilo que é do seu interesse ou do interesse do seu círculo de pessoas. Longe de ter a edição e o compartilhamento com fim primário de conquistar muitos seguidores, obter muitos likes ou de exibir somente as melhores fotos, o Instagram é utilizado, portanto, majoritariamente, para documentar momentos e estabelecer a comunicação entre pessoas próximas (MANOVICH, 2016a).

2019 não passa, de Flávio Komatsu, é uma conta no Instagram e, ao mesmo tempo, uma obra literária de fundo político, que evoca - por seus elementos pré-selecionados do real e recombinados ficcionalmente - uma revisitação aos anos de governo petista no Brasil em contraposição ao golpe de 2016, ao governo interino até o fim de 2018, às eleições de 2018, bem como sugere perspectivas de registro dos contrastes desses 16 anos que culminam em 2019, ano de descalabros políticos e desgovernos (conforme o ponto de vista da ficção). É uma obra construída no Instagram que está em processo de escrita (desde 2019) e, até o momento, seu grid é composto de 27 episódios, conforme o que se vê: 
Um romance hiper-circuitado: 2019 não passa e o curto da tradição literária Júlia de Mello Silva Oliveira • Nair Renata Amâncio • Rejane Cristina Rocha

Figura 1 - visão geral em versão mobile de 2019 não passa

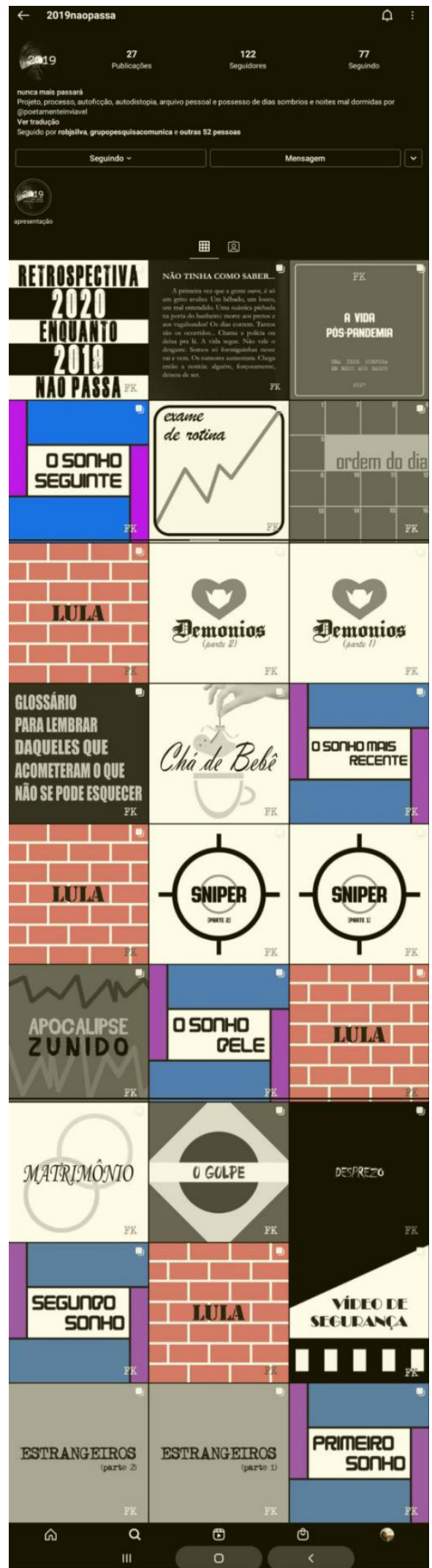

Fonte: Komatsu (2019). 
Um romance hiper-circuitado: 2019 não passa e o curto da tradição literária Júlia de Mello Silva Oliveira • Nair Renata Amâncio • Rejane Cristina Rocha

No grid, ao ser aberta uma postagem, o leitor percebe que cada episódio é construído em formato carrossel. Esse formato consiste no arranjo de até 10 imagens (conforme limite do Instagram) 1080 x 1080 pixels em sequência e depende do leitor arrastar imagem a imagem para a esquerda (como o movimento de passar a página do livro impresso) para se visualizar a próxima. Os carrosséis de imagens da obra em questão são sempre compostos por uma capa-título, aproximadamente 9 peças estáticas de texto narrativo e uma legenda-metatexto, também parte da narrativa, como se pode ver:

Figura 2 - visão em versão mobile da legenda, capa e duas imagens de texto de um episódio da narrativa de 2019 não passa

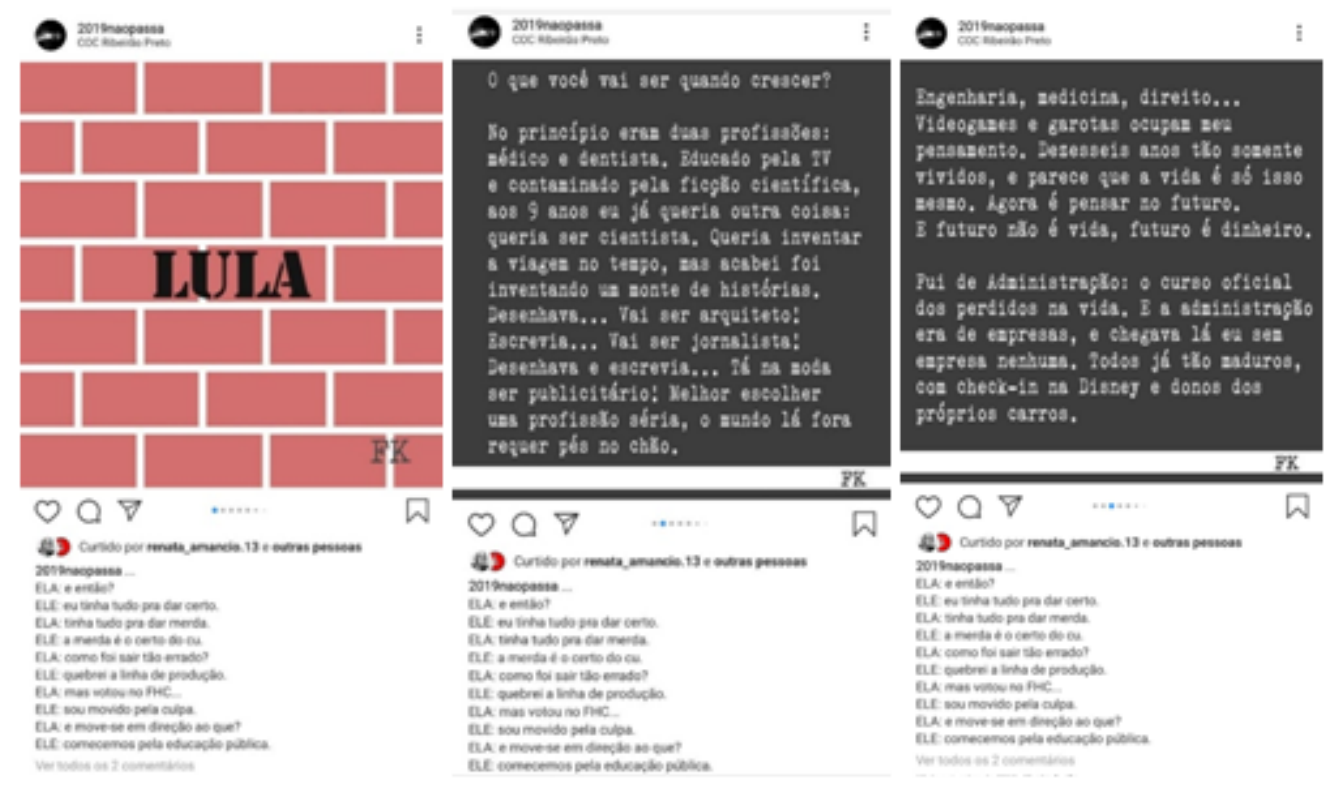

Fonte: Komatsu (2019).

\section{A teoria e o tempo: hoje o romance é, também, digital?}

Objetos como 2019... exigem uma revisão de conceitos histórico-culturalmente construídos, uma vez que novos contextos levam à produção de novos conceitos (BEIGUELMAN, 2014, p. 14). 
Um romance hiper-circuitado: 2019 não passa e o curto da tradição literária Júlia de Mello Silva Oliveira • Nair Renata Amâncio • Rejane Cristina Rocha

O fato é que cada tempo e espaço produziram suas definições de literatura, de literário, de obra, de autor, de escritor, de leitor, de poema ou de prosa e, também, dos gêneros, como "romance", de acordo com os interesses, negociações, valores e julgamentos das classes de poder (político, econômico, intelectual). As condições históricas suscitam possibilidades técnicas que se transformam ao longo do tempo, produzindo novas funcionalidades ou facultando o surgimento de outras/novas técnicas (ROCHA, 2016).

2019 não passa é "produção textual que se vale das possibilidades do meio digital para construir a sua linguagem" (ROCHA, 2014, p. 171). E as especificidades do meio, sobretudo no que concerne ao que é computacionalmente programável, no uso de seus recursos, dá à literatura novos artifícios, mecanismos e modos estético-representacionais: imagens, vídeos, sons, movimentos, cores, luzes, hiperlinks e hipertextos, interatividade, confusão ou sobreposição do autor e do leitor, performance, flerte com as artes visuais (apesar da centralidade da palavra) etc.

Para pensar o objeto deste artigo, nos concentraremos na categoria "Romance"3 e em como ela ainda é válida para a análise de 2019 não passa, ganhando também novos traços, dada a recontextualização digital e o design in grid do Instagram. A etiqueta ainda é válida porque, segundo Brandão (2005), o romance, desde sua invenção, na Grécia Antiga, é um gênero narrativo-ficcional, para o qual é central a questão da mímesis. Ele é gramatofágico (i.e., incorpora outros gêneros ou discursos), proteiforme e, nas suas (trans)formações, se constitui sob a dinâmica entre o antigo e o novo, sendo o novo a diferença em relação ao antigo, de modo que a inovação, competindo com as características antigas, faz o gênero assumir, constantemente, novas feições 4 . A categoria "romance" ganha novos traços na medida em que 2019 não passa figura também como uma inovação que passa a integrar a canonici-

\footnotetext{
3 Dentre as terminologias, regras e matérias que conformam o repertório, conforme exemplo de Even-Zohar (2017), está incluída a noção de "gêneros literários" e o conjunto de regras, padrões, temas e discussões que suscitam. A noção de gênero literário é integrante do repertório do produto literário (principalmente do repertório do texto) - repertório esse sócio-culturalmente situado, dependente da dinâmica entre os produtores, o produto, a instituição, os consumidores, o mercado etc., no tempo e no espaço. Esse repertório é mobilizado em prol da comunicação sobre um produto específico e tal noção, de gênero, funciona como uma tag que organiza o conhecimento comum sobre as formas literárias.

4 Bakhtin (2010) já teria dito que o romance é um gênero de origem grega, inacabado, em constante evolução, e um gênero que parodia outros gêneros textuais.
} 
Um romance hiper-circuitado: 2019 não passa e o curto da tradição literária Júlia de Mello Silva Oliveira • Nair Renata Amâncio • Rejane Cristina Rocha

dade dinâmica do gênero romance, enquanto modelo, nos termos de Even-Zohar (2017).

Ainda que o romance seja proteiforme e se transforme sob a dinâmica do antigo e do novo, é inegável que um conjunto de traços se cristalizou em torno do gênero no interior da cultura impressa. Dentre esses traços, podemos ressaltar a integridade da representação, que é favorecida pela integridade constituída no códice. Os novos meios (MANOVICH, 2005), entre eles o Instagram, não possibilitam, de saída, tal integridade, mas argumentamos que 2019 não passa ainda pode ser considerado um romance; um romance que coloca em xeque os traços cristalizados do gênero e testemunha a sua própria formação e transformação simultâneas. A obra nos possibilita discutir como, na mídia digital, a forma romance ganha novos traços, mas mantém a sua característica fundamental, que é a assunção de novas formas (BRANDÃO, 2005), de novos discursos e o aspecto ficcional. 2019 não passa é, portanto, um novo tipo de romance, que acompanha as mudanças e transformações da cultura e seus protocolos. Ou seja, a tradição narrativa ocidental e suas transformações, nos diversos períodos e culturas por que já passamos, amparam as narrativas digitais e elas inovam as formas anteriores de narrar, pela exploração dos limites e potencialidades do meio digital.

Todas essas mudanças no campo artístico são proporcionadas e possibilitadas, entre outras coisas, pela materialidade do digital, que tem por característica articular em um mesmo suporte diversas mídias. De acordo com Gainza (2016, p. 234), "la materialidad digital transforma los procesos de producción, circulación y recepción de las obras artísticas, donde estas mismas categorías se vuelven porosas y sus límites se vuelven difusos".

O que nos cabe perguntar é que tipo de romance é possível no aplicativo de edição e compartilhamento de imagens em ambiente mobile5. Ou, ainda, qual é o romance tornado possível pela plataforma Instagram. Por ora, nos contentaremos em discutir como

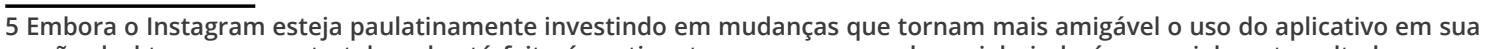
versão desktop, a pergunta tal qual está feita é pertinente porque essa rede social ainda é essencialmente voltada para o smartphone. 
Um romance hiper-circuitado: 2019 não passa e o curto da tradição literária Júlia de Mello Silva Oliveira • Nair Renata Amâncio • Rejane Cristina Rocha

2019 não passa materializa a mímesis e significa por meio do celular e da rede social de fotos e imagens instagramadas (MANOVICH, 2016c) e/ou tratadas em programas de edição, além das ferramentas do próprio Instagram.

\section{Não passa: a estética do e no instagram}

Um perfil do Instagram é composto, top to bottom, por um nome de usuário que, no romance em questão, é o título "2019 não passa"; seguido de um nome, em nosso caso, um subtítulo "nunca mais passará"; pela bio (pequena descrição do perfil e/ou do dono do perfil), em 2019..., descrição da obra: “Projeto, processo, obra por vir e já sendo, autoficção, autodistopia, arquivo pessoal e possesso, instadesagravo de dias sombrios e noites mal dormidas por @poetamenteinviavel"; pelos destaques, e, em 2019..., há somente um, intitulado "Apresentação", contendo a mesma descrição da bio e uma epígrafe de Eliane Brum; e pelo grid de postagens, composto por três colunas de imagens, de linhas infinitas.

O grid de 2019 não passa está composto por 27 postagens em formato carrossel. Cada carrossel começa com uma capa que é colorida, vetorizada, com trabalhos tipográficos e traz o título do episódio que introduz. As postagens não obedecem a uma regularidade estrita e, até o momento (agosto de 2021), a última postagem realizada foi em dezembro de 2020 .

O perfil do romance pode ser acessado se buscado, na aba explorar do app, pelo seu nome de usuário (título) ou pelo seu nome próprio (o subtítulo). Enquanto as postagens estavam acontecendo, os seguidores do perfil recebiam-nas em seu feed de notícias particular ${ }^{6}$, ou seja, entre as fotos e imagens dos perfis seguidos (entre imagens de paisagens, retratos familiares ou do cotidiano de amigos), lá estava um episódio do romance. Ou seja: um seguidor que acompanhou paulatinamente as postagens do autor,

6 Aqui é necessário lembrar que é uma atualização recente do aplicativo a possibilidade de um usuário ativar notificações para um perfil, de modo que sempre que esse perfil postar algum tipo de conteúdo, o seguidor que ativou as notificações será avisado e poderá consumir a postagem instantaneamente. 
Um romance hiper-circuitado: 2019 não passa e o curto da tradição literária Júlia de Mello Silva Oliveira • Nair Renata Amâncio • Rejane Cristina Rocha

acompanhou, ato contínuo, a construção do grid a que um novo seguidor tem acesso na sua integridade provisória7. Essa ordem de postagem, a que o leitor que acompanhou tal construção tem acesso em seu próprio feed de notícias, no grid, se daria da última postagem à primeira. Se o leitor, porém, abre o perfil do romance e resolve começar a lê-lo na sua integridade provisória, a ordem é o que menos importa, podendo-se começar a ler da última postagem à primeira ou vice-versa ou, ainda, ler os episódios conforme a ordem que quiser, independente do percurso em linha que a organização do grid suscita, horizontal e/ou verticalmente, dada a autonomia e acabamento de cada episódio.

São vários os circuitos de leitura possíveis para essa obra, de modo que, em seguida, o que se verá é a descrição de uma organização sistemática das possíveis leituras mais amplas às mais restritas em relação ao uso e à navegação no Instagram. Nossa descrição desse movimento se pautará na ideia de que os modos de ler conformam camadas de sentido, possibilitadas pela formalização material da obra e que vão se sobrepondo e sedimentando umas sobre a outras, gerando sempre novas significações. Comecemos pela última.

O modo de recepção desse texto por um leitor-seguidor, em seu feed próprio, conforma uma quinta camada de sentido, que é aquela em que um episódio ficcional, da ordinariedade da vida de uma pessoa ficcional (o protagonista do romance), se imiscui aos episódios e à ordinariedade da vida das pessoas reais do seu círculo cotidiano (familiares, amigos, famosos de quem se é fã, marcas cujas tendências se acompanha). Esse movimento é descrito por Laddaga (2002, p. 24-25) nos seguintes termos, em texto presciente a respeito do que se configuraria como um (não) espaço literário na internet:

7 Usamos o termo "integridade provisória" para chamar a atenção não apenas para o fato de que a obra, como indica o seu autor, ainda está em processo de construção como também para indicar que a sua materialidade inscricional permite que seus leitores concebam e experimentem essa integridade de distintas maneiras. 
Nenhum texto em rede pode solicitar um espaço próprio para si. A literatura não se distancia das tarefas "cotidianas", não há lugar para um "espaço literário". Não há espaço senão para a diferenciação em zonas, com transições incertas entre si [...] As produções de literatura aparecem no mesmo espaço em que se enviam as mensagens mais íntimas e se realizam práticas de trabalho: imediatamente vinculados com elas, supõe Wittig, sem se desprender inteiramente, ou desprendendo-se de um modo mais imperfeito, menos limpo, do que pode desprender-se um texto em um livro. Partes da literatura flutuam nas correntes de mensagens, nos transportes de comunicação, de uma maneira diferente da maneira de flutuar de uma obra sobre práticas de linguagem.

Mas, se acessa-se o perfil do romance, olhando para o todo de seu grid, as capas dos carrosséis de 2019 não passa, - constituídas de imagens vetorizadas e/ou tipografias sobre um fundo comum -, conformam, entre si, uma quarta camada de sentidos, uma vez que, em conjunto, constituem, por acumulação (HOSSNE, 2007), um texto imagético-textual que já prenuncia significados possíveis para o complexo de narrativas que introduzem.

Algumas das capas são iguais e possuem títulos iguais ou quase iguais, configurando uma terceira camada de sentido e uma outra possibilidade de percurso de leitura a partir das narrativas de títulos e capas comuns. "Lula”, por exemplo, é um episódio com título e capa recorrentemente esparso entre as narrativas. "Primeiro sonho", "Segundo sonho", “O sonho dele" e "O sonho mais recente" são episódios não-sequenciais, espalhados entre os demais, mas que têm em comum a mesma capa e a proximidade entre os títulos, além da temática mesma do sonho, de pesadelos políticos. No caso de "Estrangeiros", "Sniper" e de "Demônios", os títulos e capas comuns ocorrem para organizar em "parte 1" e "parte 2" os episódios cujos textos narrativos ficaram mais longos do que o formato permite e, por isso, são sequenciais, estando sempre lado a lado.

Cada capa, portanto, introduz um episódio narrativo da vida do protagonista. Essas narrativas revisitam, do presente (após ter 
adquirido consciência de classe), sua formação conservadora, que sugere, em razão dos elementos do real selecionados para compor a ficção, coincidência com a maior parte do período político democrático brasileiro depois dos anos de ditadura militar e sua conjuntura sócio-cultural. Os episódios também analisam a sociedade e a cultura do presente do personagem e seus desdobramentos políticos em relação ao passado recente pós-ditatorial evocado ficcionalmente. Assim, alternam-se olhares para o passado e para o agora ficcionais, com um balanço político-subjetivo da própria história e da suscitada história do país pós-abertura política e redemocratização. Os episódios da vida do narrador-personagem ensejam a problematização de acontecimentos sócio-políticos, ora do passado, ora do presente. Assim, junto a uma revisão de si, de um sujeito ficcional, desenha-se uma tentativa de compreensão - por parte do personagem, i.e., de sua perspectiva (da infância, adolescência e vida adulta) - de como os acontecimentos sociais, políticos e culturais do passado culminaram na situação política pela qual passa seu país em 2019. Aqui fica clara a dinâmica entre os elementos do real pré-selecionados, recombinados na construção da realidade interna da obra e a centralidade da ficção e da mímesis na produção de sentido do romance, características centrais do romance segundo Brandão (2005).

O conjunto dos episódios, por acumulação (HOSSNE, 2007), formaria um segundo estrato de sentidos, embora cada um deles possa ser lido independentemente (por exemplo, quando o leitor-seguidor recebe o episódio em seu feed particular). Já as legendas, que acompanham cada postagem, formariam um primeiro nível de significação. As legendas de cada post são sempre um diálogo entre "Ele" e "Ela". Ele é o escritor das narrativas dos carrosséis. Ela é a companheira d'Ele, que o ajuda a pensar e a problematizar o modo como narra suas vivências. Assim, Ele e Ela são personagens ficcionalizados por Ele em suas narrativas, onde representam o narrador (Ele) e Dri (Ela), i.e., o narrador e a Dri, personagens dos carrosséis, são personagens d'Ele, criados por Ele juntamente d'Ela. Há sempre um diálogo na "legenda" que acompanha o 
Um romance hiper-circuitado: 2019 não passa e o curto da tradição literária Júlia de Mello Silva Oliveira • Nair Renata Amâncio • Rejane Cristina Rocha

carrossel. Os diálogos que Ele e Ela travam nas legendas são quase sempre metalinguísticos, problematizando e discutindo a própria composição da obra em processo.

O autor ainda explora os recursos de localização do Instagram nas postagens, um hiperlink que, ao ser explorado, mostra a localização geográfica em mapa do lugar hiperlinkado, além do conjunto de fotografias tiradas por outros usuários e hiperlinkadas nessa mesma localização. Alguns dos lugares citados são Vila Brasília (bairro de São Carlos - SP), Barra Funda (bairro da capital paulistana), Programa The Noite do Danilo Gentili, Programa Super Pop, Colégio COC de Ribeirão Preto (SP), além de Gilead (república distópica de $\mathrm{O}$ conto de Aia, obra de Margareth Atwood), ou de "Classe Média", um lugar social. ${ }^{8}$

Nesse sentido, é significativo pautar como o recurso de geolocalização do Instagram - a priori pensado para que seus usuários pudessem referenciar os lugares nos quais suas fotografias foram tiradas, construindo metadados de suas postagens -, no romance 2019 não passa se converte em mais um recurso que, subvertido, contribui para a construção de sentido narrativo (FALCl, 2013).

Também funcionam como hiperlinks as hashtags presentes em todas as publicações. Algumas delas, mais constantes, são: \#literatura \#literaturadigital, \#literaturacontemporânea, \#literaturabrasileira, \#contos, \#distopia, \#autoficção, \#romancehipertextual, \#literaturaergodica, \#literaturaeletronica, \#ciberliteratura, \#instatexto, \#instaconto, \#instapoema, \#instapoesia. As hashtags reúnem imagens postadas na rede tagueadas pelo mesmo termo. Algumas delas são de uso comum de usuários do aplicativo, outras foram cunhadas por Komatsu, contendo postagens do perfil do romance e de outros perfis que administra. É o caso, por exemplo, de \#romancehipertextual.

Chama a atenção o flerte do autor com o jogo de gêneros com as hashtags e com as formas textuais dos episódios, evocando o que Brandão (2005) chamou de gramatofagia. O autor transita en-

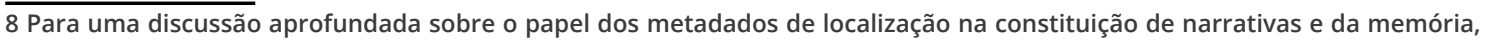
consulte Falci (2013). 
Um romance hiper-circuitado: 2019 não passa e o curto da tradição literária Júlia de Mello Silva Oliveira • Nair Renata Amâncio • Rejane Cristina Rocha

tre o conto, o romance, a poesia, o verbete de dicionário, além de explorar uma dicção que vai do descritivo ao poético, da distopia ao realismo, jogando com as vozes do narrador, da Dri (nos carrosséis), d'Ele e d'Ela (nas legendas).

Além disso, está aberta a todo e qualquer leitor, por se tratar de um perfil público de rede social, a possibilidade de interação e engajamento com as publicações, por meio de curtidas, comentários, compartilhamentos e salvamentos. Esta até poderia vir a ser uma outra rede de sentidos dentro do romance, não fosse o fato de os comentários e as interações não integrarem o conteúdo da narrativa, até o momento 9 .

\section{As redes dentro da rede: $2019 . .$. É um curto-circuito}

grid, em inglês, significa grade. Mas também significa rede elétrica. Não por acaso, a chave de leitura que sugerimos como caracterizadora deste romance de Instagram é a rede. A contextura entre tramas e tessituras de sentidos, percursos de leitura, hiperlinks e interações forma uma grande rede. Cada circuito do leitor (no feed, no grid, linear ou aleatoriamente) enforma um emaranhado de combinações de episódios e informações acessórias, conformando redes de leitura, tramas de sentido, dentro da rede do aplicativo que está na rede da Web.

Em tempo, o gesto de revisitar o passado em relação com análises do presente, pelo protagonista do romance, também funciona em rede uma vez que os processos do pensamento e da lembrança também se dão pela aleatoriedade das relações que se estabelecem entre fatos e coisas não necessariamente vinculadas. Nesse sentido, o Instagram enquanto meio possibilitador da estrutura e, especificamente, o grid, i.e., a forma é também conteúdo, e a multiplicidade de tramas de sentido é também forma. Forma

\footnotetext{
9 Em uma discussão ocorrida em uma das aulas do curso de pós-graduação Literatura Digital Brasileira (PPGLit/UFSCar), questionou-se aos estudantes por que eles acreditavam que as postagens de 2019 não passa não recebiam comentários e a resposta surpreendeu: para a maioria deles, fazer um comentário seria alterar/conspurcar a obra; ou seja, os leitores parecem transferir para uma conta da rede social (afinal, antes de qualquer coisa, é isso 2019 não passa) parâmetros de leitura e de interação típicos da cultura impressa e informados por ideias de obra e de integridade dela provenientes.
} 
de rede. Contudo, não importando o percurso de leitura feito, a acumulação e sobreposição das redes leva a um mínimo denominador comum de significação. Sendo este, portanto, também um romance-circuito, no sentido de que, em um circuito elétrico (não nos esqueçamos que grid em inglês é rede elétrica), a energia se ramifica para vários pontos com o mesmo intuito, prover energia. Igualmente, não importa por onde se comece a ler o 2019... ou que percurso se faz, porque o conjunto de textos proporciona sempre um mesmo "mínimo repertório comum" de informação narrativa.

Assim, ainda que Instagram originalmente seja uma rede social de edição e compartilhamento de fotos, cujas postagens, em sua maioria, se dão sob o "modo doméstico", é importante levar em conta as cooptações que a arte, especificamente a literatura, faz da rede social e de suas práticas, rasurando e alterando os protocolos padrões de uso do aplicativo, o que Machado (2007) chamou de "desprogramação da técnica". Nesse sentido, ao se pensar uma categoria tradicional e culturalmente fixada como a de gênero literário e, especificamente, de romance, esses conceitos podem (e devem) abarcar, por exemplo, obras de literatura digital como o romance de Instagram. Isso porque o próprio gênero, por definição, conforme Brandão (2005) e Bakhtin (2010), se (trans)forma constantemente a partir de outros gêneros, discursos, no jogo entre o antigo e o novo, entre ficção e mímesis.

Assim, embora as características fundamentais do gênero se mantenham, dada sua definição conceitualmente aberta, a sua recontextualização digital - observada, p. e. em seu design in grid (em grade e em rede) e no uso que faz de recursos da rede social na criação narrativa - exige um olhar atento para o que se constrói fora dessas características, dessas especificidades, sob o risco de não se conseguir apreender como a obra materializa a convergência entre o impresso e o digital (JENKINS, 2009). 2019 não pas$s a$ é um romance hiper-circuitado que coloca em curto a tradição literária e as suas especificidades, expandindo a rede de fiação da literatura para o inelutável agora. 


\section{Referências}

BAKHTIN, Mikhail. Questões de literatura e de estética (a teoria do romance). São Paulo, Hucitec Editora, 2010.

BEIGUELMAN, Giselle. Reinventar a memória é preciso. In: Futuros possíveis: artes, museus e arquivos digitais. São Paulo: EDUSP/FAPESP/Itaú Cultural/Peirópolis, 2014, p. 12-33.

BRANDÃO, Jacyntho L. A invenção do romance: narrativa e mimese no romance grego. Brasília, Editora Universidade de Brasília, 2005.

DARNTON, Robert. Parte III - A palavra impressa. In: DARNTON, Robert. $\mathbf{O}$ beijo de Lamourette: mídia, cultura e revolução. São Paulo: Companhia das Letras, 1990.

DIGITAL 2021: BRAZIL. DataReportal, 2021. Disponível em: https://datareportal.com/reports/digital-2021-brazil. Acesso em: 3 mai. 2021.

DIGITAL 2021: GLOBAL DIGITAL OVERVIEW. DataReportal, 2021. Disponível em: https://datareportal.com/reports/digital-2021-global-overview-report. Acesso em: 3 mai. 2021.

EVEN-ZOHAR, Itamar. Polisistemas de cultura. Tel Aviv, Universidad de Tel Aviv -Laboratorio de investigación de la cultura, 2017.

FALCl, Carlos Henrique Rezende. Lugares imaginários em rede - narrativas de memória em ambientes programáveis. Texto Digital, Florianópolis, v. 9, n. 1, p. 213-226, jul. 2013.

GAINZA, C. Nuevos escenarios literarios: hacia una cartografía de la literatura digital latinoamericana. In: MÜLLER, G.; GUERRERO, GUSTAVO; LOY, BENJAMIN (Eds.). World editors: Dynamics of Global Publishing and the Latin American Case between the Archive and the Digital Age. Berlim/Boston: De Gruyter, 2021. p. 331-349.

GAINZA, Carolina. Narrativas y poéticas digitales en América latina. Producción literaria en el capitalismo informacional. Santiago de Chile: Ed. Cuarto Propio, 2018.

GAINZA, Carolina. Literatura chilena en digital: mapas, estéticas y conceptualizaciones. Revista. Chilena de literatura. Santiago, n. 94, p. 233-256, dez. 2016. 
Um romance hiper-circuitado: 2019 não passa e o curto da tradição literária Júlia de Mello Silva Oliveira • Nair Renata Amâncio • Rejane Cristina Rocha

GARRAMUÑO, F. Frutos estranhos: sobre a inespecificidade na estética contemporânea. Rio de Janeiro: Rocco, 2014.

HAYLES, Katherine. Literatura Eletrônica: novos horizontes para o literário. Passo Fundo: UPF/São Paulo: Global, 2009

HOSSNE, Andrea S. Degradação e acumulação: considerações sobre algumas obras de Luiz Ruffato. In: HARRISON, Marguerite Itamar. Uma cidade em camadas: ensaios sobre o romance Eles eram muitos cavalos de Luiz Ruffato. Vinhedo: Ed. Horizonte, p. 18-42, 2007.

JENKINS, Henry. Cultura da Convergência. São Paulo, Aleph, 2009. KLUCINSKAS, Jean; MOSER, Walter. A estética à prova da reciclagem cultural. Scripta, v. 11, n. 20, 2007.

KOMATSU, Flávio. 2019 não passa: nunca mais passará. Instagram, 2019. Disponível em: https://www.instagram.com/2019naopassa/?hl=pt-br. Acesso em: 2 ago. de 2021.

LADDAGA R. Uma fronteira do texto público: literatura e meios eletrônicos. In: OLINTO, H. K.; SCHOLLHAMMER, K. E. (Orgs.). Literatura e mídia. Rio de Janeiro: PUC/Loyola, 2002. p. 17-31.

MACHADO, Arlindo. Arte e mídia. Rio de Janeiro, Zahar, 2007.

MANOVICH, Lev. El lenguaje de los nuevos medios de comunicación. Trad. Oscar Fontodrona. Barcelona: Paidós, 2005.

MANOVICH, Lev. Subjects and Styles in Instagram Photography (part 1). Manovich, 2016a. Disponível em: http://manovich.net/index.php/projects/subjects-and-styles-in-instagram-photography-part-1. Acesso em: 7 dez, 2019.

MANOVICH, Lev. Subjects and Styles in Instagram Photography (part 2). Manovich, 2016b. Disponível em: http://manovich.net/index.php/projects/subjects-and-styles-in-instagram-photography-part-2. Acesso em: 6 dez. 2019.

MANOVICH, Lev. Notes on Instagrammism and mechanisms of contemporary cultural identity (andalso photography, design, Kinfolk, kpop, hashtags, mise-en-scène, and состояние). Manovich, 2016c. Disponível em: http://manovich.net/index.php/projects/notes-on-instagrammism- 
Um romance hiper-circuitado: 2019 não passa e o curto da tradição literária Júlia de Mello Silva Oliveira • Nair Renata Amâncio • Rejane Cristina Rocha

-and-mechanisms-of-contemporary-cultural-identity. Acesso em: 5 dez. 2019.

MANOVICH, Lev. Designing and Living Instagram Photography:

Themes, Feeds, Sequences, Branding, Faces, Bodies. Manovich, 2016d. Disponível em: http://manovich.net/index.php/projects/designing-and-living-instagram-photography. Acesso em: 4 dez. 2019.

ROCHA, Rejane Cristina. Além do livro: literatura e novas mídias.

Estudos de Literatura Brasileira Contemporânea, n. 47, p. 11-17, 2016. Disponível em: https://periodicos.unb.br/index.php/estudos/article/view/10096/8922. Acesso em: 3 dez. 2019.

ROCHA, Rejane C. "Monstro esperançoso": a respeito de Oratório, de André Vallias. Estudos de literatura brasileira contemporânea.

Brasília, n. 47, p. 157-184, 2016. Disponível em: https://periodicos.unb. br/index.php/estudos/article/view/10096/8922. Acesso em: 2 dez. 2019.

ROCHA, Rejane C. Contribuições para uma reflexão sobre a literatura em contexto digital. Revista da Anpoll. Florianópolis, n³6, p. 160-186, 2014. Disponível em https://revistadaanpoll.emnuvens.com.br/revista/ article/view/680/738. Acesso em: 2 dez. 2019.

RECUERO, Raquel. Redes sociais na internet. Porto Alegre: Sulina, 2009. 